\title{
BULLETIN of the
}

\section{AUSTRALIAN MATHEMATICAL SOCIETY}

\section{Volume 30 Number 2}

October 1984

Metric spaces which cannot be isometrically embedded in Hilbert space

by Yang Lu and Zhang Jing-Zhong

.. 161

A note on the central limit theorem for geodesic random walks

by Gilles Blum

A remark on products of locally soluble groups

by C. J. B. Brookes and Howard Smith

. 175

Two-sided localization in semiprime FBN rings by M. H. Upham .

Generalized convexity in nondifferentiable programming by Bevil M. Glover ..

Elliptic differential operators and diffusion processes

by Heinz Bauer

Isometries and certain dynamical systems

by Saber Elaydi and Hani R. Farran

A chain rule for differentiation with applications to multivariate Hermite polynomials by C. S. Withers

Nemitsky operators between Orlicz-Sobolev spaces by Grahame Hardy..

The mathematics of hysteresis

by Ulrich Hornung..

On the commutativity of torsion free rings

by Evegelos Psomopoulos..

Compressible matrix rings

by Efraim P. Armendariz and Jae Keol Park ..

On the boundary behaviour of Bloch and normal functions

by Rauno Aulaskari .

Linear systems of nonoscillatory differential equations with delayed arguments

by K. Gopalsamy ..

\section{ABSTRACTS OF AUSTRALASIAN PhD THESES}

Wave propagation in density stratified fluids

by John Anthony Gear

Minimum mean squared error estimation

by Victor Charles Drastik..

The Regge calculus in numerical relativity \section{by Leo Brewin \\ The Regre}




\section{BULLETIN OF THE AUSTRALIAN MATHEMATICAL SOCIETY}

Editor: Sidney A. Morris

\author{
Deputy Editor: \\ K. R. Pearson \\ Honorary Editor: \\ B. H. Neumann
}

\section{Associate Editors}
Robert S. Anderssen
Alan L. Andrew
B. J. Gardner
J. R. Giles
B. D. Craven
Brian A. Davey
P. Donovan
J. A. Eccleston
J.R. J. Groves
J. A. Hempel
D. A. Holton
D. C. Hunt

P. E. Kloeden

Rodney Nillsen

Sheila Oates-Williams
A. J. van der Poorten

J. H. Rubinstein

Leon Simon
Ross Street

G. Szekeres

D. G. Tacon

Colin J. Thompson

H. B. Thompson

Rudolf Výborný

\section{Assistant Editors}

Robert S. Anderssen

M. S. Brooks

\section{INFORMATION FOR AUTHORS}

The BULLETIN of the Australian Mathematical Society aims at quick publication of original research in all branches of mathematics. Timely expository articles are also welcomed.

To ensure speedy publication, editorial decisions on acceptance or otherwise are taken quickly, normally within a month of receipt of the paper. Papers are accepted only after being evaluated by the Editor and an Associate Editor or another expert. Of course responsibility for the correctness of results published in the BULLETIN remains with the authors.

For a paper to be acceptable for publication, not only should it contain new and interesting results but also

(i) the exposition should be clear and attractive, and

(ii) the manuscript should be in publishable form, without revision.

Nevertheless some meritorious papers will have to be rejected because speed of publication involves space limitations.

Authors should submit THREE clean, high quality copies to

Dr S. Oates-Williams,

Department of Mathematics, University of Queensland,

St. Lucia, Queensland, 4067, Australia

but should not send the original typescript of their papers, as material submitted to the BULLETIN will usually not be returned. Authors should note that each paper submitted must include an abstract and one or more classification numbers following the 1980 Mathematics Subject Classification.

As even minor revisions are generally not permitted, authors should read carefully all the details listed on the inside back cover.

\section{Abstracts of PhD Theses}

The BULLETIN endeavours to publish abstracts of all accepted Australasian $\mathrm{PhD}$ theses in mathematics. One restriction, however, is that the abstract must be received by the Editor within 6 months of the degree being approved.

(C) Copyright Statement. Where necessary, permission to photocopy for internal or personal use or the internal or personal use of specific clients is granted by the Treasurer. Australian Mathematical Publishing Association, Inc., for libraries and other uses registered with the Copyright Clearance Center (CCC). provided that the base fee of \$A2.00 per copy of article is paid directly to CCC, 21 Congress Street, Salem, MA 01970, U.S.A. Special requests should be addressed to the Treasurer. Australian Mathematical Publishing Association, Inc., c/- Department of Mathematics, University of Queensland, St. Lucia, Qld., 4067. Australia. Serial-fee code: 0004-9727/84\$A2.00+0.00 